\title{
Profile of Clients \& HIV positive patients attending the ICTC of a tertiary care center of Bihar: A situational analysis
}

Arshad Ayub ${ }^{1}$, Geetika Singh ${ }^{2}$, Shamshad Ahmad ${ }^{3}$, Saket Shekhar ${ }^{4}$, Bhojraj Palariya ${ }^{5}$, Amita Rathore ${ }^{6}$, Pragya Kumar $^{7}$, Neeraj Agarwal ${ }^{8}$

${ }^{1}$ Ex-Senior Resident, Department of Community \& Family Medicine, All India Institute of Medical Sciences, Patna, Bihar; ${ }^{2}$ Ex Senior Resident, Department of Community \& Family Medicine, All India Institute of Medical Sciences, Patna, Bihar; ${ }^{3}$ Assistant Professor, Department of Community \& Family Medicine, All India Institute of Medical Sciences, Patna, Bihar; ${ }^{4}$ Senior Resident, Department of Community \& Family Medicine, All India Institute of Medical Sciences, Patna, Bihar; ${ }^{5}$ Senior Nursing Officer, All India Institute of Medical Sciences, Patna, Bihar; ${ }^{6}$ Nursing Officer, All India Institute of Medical Sciences, Patna, Bihar; ${ }^{7}$ Additional Professor, Department of Community \& Family Medicine, All India Institute of Medical Sciences, Patna, Bihar; ${ }^{8}$ Ex -Professor and Head, Department of Community \& Family Medicine, All India Institute of Medical Sciences, Patna, Bihar

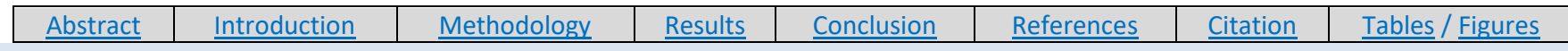

\section{Corresponding Author}

Dr. Shamshad Ahmad, Department of Community \& Family Medicine, All India Institute of Medical Sciences, Phulwari Sharif, Patna, Bihar - 801507

E Mail ID: ahmad.aiims.patna@gmail.com

\section{Citation}

Ayub A, Singh G, Ahmad S, Shekhar S, Palariya B, Rathore A, Kumar P, Agarwal N. Profile of Clients \& HIV positive patients attending the ICTC of a tertiary care center of Bihar: A situational analysis. Indian J Comm Health. 2021;33(2):282-287. https://doi.org/10.47203/IJCH.2021.v33i02.010

Source of Funding: Nil Conflict of Interest: None declared

\section{Article Cycle}

Received: 22/12/2021; Revision: 08/04/2021; Accepted: 27/05/2021; Published: 30/06/2021

This work is licensed under a Creative Commons Attribution 4.0 International License.

\section{Abstract}

Background: The services provided in an ICTC help in awareness about HIV and help the clients to undergo HIV test in a comfortable and confidential environment. Periodical evaluation of counseling, testing, and referral services is mandatory to find out any existing deficits and barriers of all functions of ICTCs. Objectives: To study the socio-demographic profile of ICTC attendees and to find out sero-positivity of these clients. Methods: The present study was carried out among ICTC attendees in the ICTC unit, at All India Institute of Medical Sciences of Patna district. A retrospective collection of data from available records of all clients who attended ICTC of our hospital between January 2019 and December 2019 was carried out after approval from institutional research and ethics committee. Results: A total of 28876 clients were tested during JanuaryDecember 2019 and among them all (100\%) of tests were provider initiated. Out of the total attendees, $223(0.77 \%)$ were found to be positive. It was also observed that the number of clients attending the ICTC has increased every month. Conclusion: It shows a high illiteracy and high spouse positive rate among the reactive cases. The young age group was found to be affected more and it definitely raises a cocern.

\section{Keywords}

\section{ICTC; HIV; HIV Tests; Counselling}

\section{Introduction}

HIV counselling and testing services were started in India in 1997.(1) An ICTC is a place where a person is counselled and tested for HIV, of his own free will or as advised by a medical provider. The main functions of an ICTC are, conducting HIV diagnostic tests., providing basic information on the modes of HIV transmission, and promoting behavioral change to reduce vulnerability and linking people with other HIV prevention, care and treatment services. These services provide awareness and accurate information about HIV and help the clients to undergo HIV test in a comfortable, supportive and confidential environment.

In financial year 2015-16, more than 29 million clients accessed counselling and testing services in the ICTC throughout the country.(1)

The adult HIV prevalence at national level has continued its steady decline from an estimated peak of $0.38 \%$ in 2001-03 through $0.34 \%$ in 2007, $0.28 \%$ in 2012 and $0.26 \%$ 
in 2015 to $0.22 \%$ in 2017 and remained same in 2019 .

Overall, the estimated adult (15-49 years) HIV prevalence trend has been declining in India since the the year 2000 and has been stabilizing in recent years.(2)

Barriers to voluntary counselling and testing (VCT) are negligence, negative perceptions of testing services, lengthy pre- and post-test counseling, and shortage of good counselors.(3,4) A total of 90.52 lakh clients tested for HIV in the year 2011-2012.(5) Periodical evaluation of counseling, testing, and referral services is mandatory to find out any existing deficits and barriers of all functions of ICTCs. A detailed Socio-demographic information about the clients will help in understanding the factors associated with increased or decreased testing of HIV.

\section{Aim \& Objective}

To study the socio-demographic profile of ICTC attendees and to find out sero-positivity of these clients.

\section{Material \& Methods}

Study Type: Cross Sectional study, Study population : A retrospective collection of data from available records of all clients who attended ICTC of our hospital between January 2019 and December 2019 was carried out after approval from institutional research and ethics committee approval. Study Area: The present study was carried out among ICTC attendees in the Department of Community \& Family Medicine (CFM), ICTC unit, at All India Institute of Medical Sciences of Patna district, Bihar, India. Study Duration: 3 months (January 2020 to March 2020) Sample Size : The present study included 28876 ICTC attendees, who were either volunteers or referred by various departments of our institute. The ICTC counselors collected their anonymous and unlinked data in registers and logbooks as per National AIDS Control Organization (NACO) guidelines under strict confidentiality. Data accessed from the records included age, sex, marital status, education and occupational status, behavioral patterns and HIV status of the couples.

Ethical approval: Ethical approval from Institutional Ethics committee was taken before the commencement of the study. Consent: As the data was taken from the records retrospectively, consent was not applicable.

Sample collection and processing: All the ICTC attendees had relevant pretest counseling and written informed consent was sought before HIV testing was carried out. Five milliliters $(\mathrm{mL})$ venous blood sample was collected in a sterile plain container from all clients who consented for HIV testing. Blood was allowed to clot for $30 \mathrm{~min}$ at room temperature $\left(25-30^{\circ} \mathrm{C}\right)$ and serum was separated after centrifugation at low speed. The serum samples were then stored at $4^{\circ} \mathrm{C}$ and were tested within $24 \mathrm{~h}$.

HIV serology: HIV antibodies were tested by the three rapid tests protocol as per the guidelines laid down by the World Health Organization (WHO testing strategy III) and the testing policy of NACO, Government of India. $(5,6)$ The blood was initially screened using Meriscreen Rapid test kit. Those found to be reactive were subjected to Combs Test (second test) followed by Immunodot test (third test). The samples were considered as positive when found reactive by all three different methods. All tests were done according to manufacturer's instructions. If the test was non-reactive, attendees were counselled regarding preventive measures for HIV. If the test was reactive, then the attendees were advised appropriately, the counsellor undertook post-test counselling and the patients were referred for care, support and treatment programs to their respective ART centers. All positive test results were disclosed only after posttest counseling of the patients. Under the parent-to-child transmission of HIV/AIDS (PPTCT) Programme, HIV testing was also offered to all pregnant women reporting to the Obstetrics and Gynecology Department of AlIMS, Patna. Similar counseling and testing protocol were followed in all these antenatal cases.

Statistical analysis: The data were analyzed for the frequency, proportion,95\% Confidence interval and the possible associations were found out using the Chi-square tests. The analysis was done using 'Statistical Package for the Social Sciences (SPSS)' statistical software. Statistical significance was defined when $P$ value is less than 0.05 .

\section{Results}

In this study, a total of 28876 clients were tested during January-December 2019 and among them all (100\%) of tests were provider initiated. Out of the total attendees, $223(0.77 \%)$ were found to be positive. It was also observed that the number of clients attending the ICTC has increased every month [Figure-1].The number of reactive cases didn't follow a uniform trend, it was highest in April 29(1.3\%) followed by February 21(1.1\%) and August $27(0.99 \%)$. The lowest proportion of recorded reactive cases were in the month of January $7(0.4 \%)$ [Figure-1] \& [Table]

The total number of clients was 28876 out of which 28136 were from Bihar only and rest 740 were from different regions from India and few from Nepal. [Figure-2] shows the number of clients coming from different administrative divisions of Bihar. It is clear that maximum number of attendees were from Patna division (16321) followed by Tirhut (2950) and Magadh division (2529). Minimum attendees were from Purnea (494) and Bhagalpur divisions (318). The number of reactive cases were also highest from the same divisions (maximum i.e. 106 from Patna division followed by Tirhut i.e. 20).The least number of reactive cases were from Kosi (3) and Darbhanga.(6)

[Table 2] shows the distribution of clients and reactive patients, attending the ICTC center across their sex and age. Maximum attendees were from 25-44 years age group followed by the age group of 45-64 years. Proportion of males were significantly higher among all age groups except $25-44$ years age group where females 
were more than males. It is evident from above table that males were more among the reactive cases (63\%) while females were $37 \%$. Among males, the maximum (60.29\%) reactive cases were from the 25 to 44 years age group followed by $30.14 \%$ from $45-64$ years age group. Similarly, among females, maximum (51.25\%) were from the 25 to 44 years age group followed by $31.25 \%$ from $45-64$ years age group. Only one reactive case was there aged more than 65 years. The association was not found to be statistically significant.[Table 3]

The various characteristics of the clients with a reactive result were not complete and consistent as while recording the data, there were various factors such as hesitation, hurry, depression, feeling ashamed etc. that hindered a complete data collection. Data regarding education was present from only 107 out of 223 reactive cases and showed that $68(63.5 \%)$ reactive cases were literate. Similarly, data regarding history of migration was available from only 69 reactive cases which showed 10 (14.4\%) of people having a history of migration, and around $29 \%$ of the spouse of the reactive cases were found to be reactive.

When asked about possible risk behavior $(\mathrm{N}=164)$ the most common risk behavior was found to be casual/noncommercial/non regular partner (42\%) followed by regular partner/spouse (21.9\%) and Unknown (21.3\%). Least common one was homosexual transmission (0.61\%).

\section{Discussion}

In 2015, adult HIV prevalence is estimated at $0.30 \%$ among males and at $0.22 \%$ among Females.(8) Among the States/UTs, in 2015, Manipur has shown the highest estimated adult HIV prevalence of $1.15 \%$, followed by Mizoram (0.80\%), Nagaland (0.78\%), Andhra Pradesh \& Telangana (0.66\%), Karnataka (0.45\%), Gujarat (0.42\%) and Goa (0.40\%). Besides these States, Maharashtra, Chandigarh, Tripura and Tamil Nadu have shown estimated adult HIV prevalence greater than the national prevalence $(0.26 \%)$, while Odisha, Bihar, Sikkim, Delhi, Rajasthan and West Bengal have shown an estimated adult HIV prevalence in the range of $0.21-0.25 \%$. All other States/UTs have levels of adult HIV prevalence below $0.20 \% .(7)$

In our study the proportion was $0.77 \%$ among the attendees which is higher than the state, while a study done in a tertiary care hospital in Delhi shows an average of $6.3 \%$ reactive cases over 5 years.(8)

The gender pattern among both attendees and reactive cases remains the same as found in studies done in other parts of the country. In our study $52.6 \%$ male and $47.4 \%$ female clients attended the ICTC while in a study done by Chellaiyan et al in Delhi had 68\% males and 32\% females were there. Similarly a study from Odisha shows a $67 \%$ of total clients being male and 33\% females.(9) Among positive/reactive cases $63 \%$ were males and $37 \%$ were females in our study, while in a study done by Dutt et al $56 \%$ were males and $44 \%$ were females.(10)

WHO's health specific age classification was used to classify the clients according to age in the present study.(11) And it was found that maximum attendees (36.3\%) were from $25-44$ years age group followed by the age group of $45-64$ years $(25.2 \%)$ as this is the most sexually active age group and emphasizes the need of youth specific interventions or mandatory sex education, so that these young adults can be prepared beforehand. A study from Delhi shows similar pattern of maximum attendees from 25-49 year age group.(8) The number of reactive cases were highest in April (1.3\%) followed by February (1.1\%) and August (0.99\%). The lowest proportion of recorded reactive cases were in the month of January $(0.4 \%)$

In our study, $29 \%$ of the spouse's status was reactive and $47 \%$ was unknown. Dash et al in Odisha found that among reactive cases, $95.5 \%$ where male partner/husband was positive and female partner/wife negative, while $4.5 \%$ where male partner/husband negative and female partner/wife was positive.(9) The same study shows that majority of HIV-seropositives, were less educated which is similar to our study (illiteracy-36.4\%).(9)

Among reactive females' majority (84.09\%) were housewives. A study done by Kommula et al also shows similar pattern.(11) It was found in the present study that majority of the male reactive patients (26.31\%) were farmers which is also similar (39.8\%) to the study carried out by Kommula et al.(11)

The most common Pattern of risk behavior was found to be casual, non-commercial, non-regular intercourse with opposite gender (42\%). Which is similar (highest) in the study by Kommula et al.(11) Risk behavior like blood transfusion, vertical transfusion, homosexuality and intravenous drug abuse were low and these findings are almost similar to national figures. People with high risk behavior and the spouse of the affected person need to be counselled regarding all levels of prevention of the disease. HIV patients should be counselled/educated regarding the antiretroviral therapy that prolongs the survival and decreases the viral load and transmission of the disease.

\section{Conclusion}

The study involves huge and diverse data $(28,868)$ both from the state and outside the state as well, which is good for having an estimate of the actual picture. The monthly variation in the number of the clients and reactive cases was found. Also it shows a high illiteracy and high spouse positive rate among the reactive cases. The young age group was found to be affected more and it definitely raises a concern and must be given priority in terms of all levels of prevention. 


\section{Recommendation}

When we understand the trend of the disease (monthly) and the sociodemographic factors attached, it helps in understanding the current situation of the disease in the state. It definitely opens the doors of new dimensions in the research.

\section{Limitation of the study}

The various characteristics of the reactive clients couldn't be associated with other variables because of incomplete /inconsistent responses.

\section{Relevance of the study}

High illiteracy among the reactive cases as well as the young age group affected more, are the findings from the reactive cases from the state of Bihar. It also adds the trend of the disease during the calender months.

\section{Authors Contribution}

AA: Concept, Definition of intellectual content, Literature search, Data acquisition, Data analysis, Statistical analysis, Manuscript preparation, Manuscript editing. GS: Literature search, Data acquisition, Data analysis, Statistical analysis, Manuscript preparation. SA: Literature search, Data acquisition, Data analysis, Statistical analysis, Manuscript preparation, Manuscript editing. SS: Literature search, Data analysis, Statistical analysis, Manuscript preparation. BP: Data acquisition. AR,PK,NA: Manuscript editing, Manuscript review.

\section{Acknowledgement}

We acknowledge our Residents Doctors, Nursing officer and the lab technicians for their sincere and responsible work.

\section{References}

1. Integrated Counselling and Testing Centre | National AIDS Control Organization | MoHFW | Gol. Available from: http://naco.gov.in/integrated-counselling-and-testing-centre (Last accessed on 25.06.2021)

2. routinizing_hiv_testing.pdf. Available from: http://pdc.ceu.hu/archive/00003268/01/routinizing hiv testing.p df (Last accessed on 25.06.2021)

3. Dyk AC van, Dyk PJ van. "To know or not to know": Service-related barriers to Voiuntary HIV Counseling and Testing (VCT) in South Africa. Curationis. 2003 Mar 27;26(1):4-10.

4. Chellaiyan VG, Raut DK, Khokhar A. Integrated counseling and HIV testing centers of Delhi: An evaluation. J Family Med Prim Care. 2018;7(4):791-5.

5. National_Guidelines_for_HIV_Testing_21Apr2016.pdf. Available from:

http://www.naco.gov.in/sites/default/files/National Guidelines f or HIV Testing 21Apr2016.pdf

6. Annual Report 2015-16.pdf. Available from: http://naco.gov.in/sites/default/files/Annual\%20Report\%20201516.pdf (Last accessed on 25.06.2021)

7. recent-trend-of-hiv-infection-at-ictc-in-a-tertiary-care-hospital-innorth-india.pdf. Available from https://www.archivesofmedicine.com/medicine/recent-trend-ofhiv-infection-at-ictc-in-a-tertiary-care-hospital-in-north-india.pdf (Last accessed on 25.06.2021)

8. Dash M, Padhi S, Sahu S, Mohanty I, Panda P, Parida B, et al. HIV counseling and testing in a tertiary care hospital in Ganjam district, Odisha, India. Journal of Postgraduate Medicine. 2013 Apr 1;59(2):110.

9. Dutt R, Chaudhuri S, Goswami S. Profile of HIV positive clients: an ICTC record based retrospective study. Int J Community Med Public Health. 2017 Jul 22;4(8):3018.

10. SeriesM_74e.pdf. Available from: https://unstats.un.org/unsd/publication/SeriesM/SeriesM 74e.pd f (Last accessed on 25.06.2021)

11. Kommula DVM, Mishra DAK. Profile Of HIV Positive Clients In An ICTC Of A Private Medical College, Andhra Pradesh: A Situational Analysis. 3:6.

\section{Tables}

TABLE 1 TOTAL NUMBER OF CLIENTS ( $\mathrm{N}=28136)$ FROM DIFFERENT ADMINISTRATIVE DIVISIONS OF BIHAR $(\mathrm{N}=\mathbf{1 7 6})$

\begin{tabular}{|ll|}
\hline Administrative divisions & Number of clients (N=28136) \\
\hline Magadh & $2529(8.98 \%)$ \\
\hline Kosi & $825(2.93 \%)$ \\
\hline Darbhanga & $1367(4.85 \%)$ \\
\hline Tirhut & $2950(10.48 \%)$ \\
\hline Saaran & $1959(6.96 \%)$ \\
\hline Purnea & $494(1.75 \%)$ \\
\hline Bhagalpur & $318(1.13 \%)$ \\
\hline Patna & $16321(58.00 \%)$ \\
\hline Munger & $1373(4.87 \%)$ \\
\hline
\end{tabular}


TABLE 2 AGE AND SEX WISE DISTRIBUTION OF CLIENTS ( $\mathrm{N}=28867$ ) AND REACTIVE PATIENTS ( $\mathrm{N}=\mathbf{2 1 6}$ ) ATTENDING ICTC CENTER FOR HIV TESTING

\begin{tabular}{|c|c|c|c|c|c|c|}
\hline \multicolumn{3}{|c|}{ Total Clients ( $\mathrm{N}=28867$ ) } & \multicolumn{4}{|c|}{ Total Reactive patients ( $\mathrm{N}=\mathbf{2 1 6}$ ) } \\
\hline Age Category & $\begin{array}{l}\text { Male } \\
\text { (Freq, Row \% \& } \\
95 \% \mathrm{Cl} \text { ) }\end{array}$ & $\begin{array}{l}\text { Female } \\
\text { (Freq, Row \% } \\
\& 95 \% \mathrm{Cl} \text { ) }\end{array}$ & P-values & $\begin{array}{l}\text { Male } \\
\text { (Freq, Column } \\
\% \& 95 \% \mathrm{Cl} \text { ) }\end{array}$ & $\begin{array}{l}\text { Female } \\
\text { (Freq, Column \% } \\
\& 95 \% \mathrm{Cl} \text { ) }\end{array}$ & $\begin{array}{l}\mathrm{P} \text { - } \\
\text { values }\end{array}$ \\
\hline $1-14$ years & $\begin{array}{l}1694 \\
(65.43 \%, 63.5- \\
67.4)\end{array}$ & $\begin{array}{l}895 \\
(34.56 \%, 32.7- \\
36.4)\end{array}$ & $<0.0001$ & $\begin{array}{l}4 \quad(2.94 \%, 1.15- \\
7.32)\end{array}$ & $\begin{array}{l}5 \quad(6.25 \%, \quad 2.7- \\
13.81)\end{array}$ & 0.409 \\
\hline $15-24$ years & $\begin{array}{l}3041 \\
(53.6 \%, \quad 52.3- \\
54.8)\end{array}$ & $\begin{array}{l}2633 \\
(46.4 \%, \quad 45.1- \\
47.7)\end{array}$ & 0.08 & $\begin{array}{l}9(6.61 \%, 3.52- \\
12.10)\end{array}$ & $\begin{array}{l}8 \quad(10.00 \% \\
18.51)\end{array}$ & 0.527 \\
\hline $25-44$ years & $\begin{array}{l}4895 \\
(46.7 \%, \quad 45.7- \\
47.6)\end{array}$ & $\begin{array}{l}5587 \\
(53.3 \%, \quad 52.3- \\
54.2)\end{array}$ & $<0.0001$ & $\begin{array}{l}82 \quad(60.29 \%, \\
51.9-68.13)\end{array}$ & $\begin{array}{l}41 \quad(51.25 \%, 40.4- \\
61.89)\end{array}$ & 0.248 \\
\hline 45-64 years & $\begin{array}{l}3722 \\
(51.0 \%, \quad 49.8- \\
52.1)\end{array}$ & $\begin{array}{l}3578 \\
(49.0 \%, \quad 47.8- \\
50.1)\end{array}$ & 0.001 & $\begin{array}{l}41 \quad(30.14 \%, \\
23.07-38.32)\end{array}$ & $\begin{array}{l}25(31.25 \%, 22.1- \\
42.07)\end{array}$ & 0.011 \\
\hline 65 years & $\begin{array}{l}1821 \\
(64.5 \%, \quad 62.4- \\
66.2)\end{array}$ & $\begin{array}{l}1001 \\
(35.5 \%, \quad 33.7- \\
37.2)\end{array}$ & $<0.0001$ & $0(0 \%, 0.00-2.75)$ & $\begin{array}{l}1 \quad(1.25 \%, \quad 0.22- \\
6.75)\end{array}$ & $\begin{array}{l}0.370 \\
\text { (Fisher's }\end{array}$ \\
\hline Total & $\begin{array}{l}15173 \\
(52.6 \%)\end{array}$ & $\begin{array}{l}13694 \\
(47.4 \%)\end{array}$ & Total & $136(62.96 \%)$ & $\begin{array}{l}80 \\
(37.03 \%)\end{array}$ & Exact) \\
\hline
\end{tabular}

\section{TABLE 3 VARIOUS CHARACTERISTICS OF REACTIVE PATIENTS (FREQUENCY, PROPORTION)}

\begin{tabular}{|l|l|}
\hline Female (44) & \\
\hline House wife & $37(84.09 \%)$ \\
\hline Skilled & $1(2.27 \%)$ \\
\hline Unskilled & $6(13.63 \%)$ \\
\hline Bale (57) & \\
\hline Semi-skilled & $6(10.52 \%)$ \\
\hline Skilled & $11(19.29 \%)$ \\
\hline Unskilled & $29(50.87 \%)$ \\
\hline Professional & $8(14.03 \%)$ \\
\hline Education (N=107) & $3(5.26 \%)$ \\
\hline Literate & \\
\hline Illiterate & $68(63.55 \%)$ \\
\hline Spouse status (N=151) & $39(36.44 \%)$ \\
\hline Reactive & \\
\hline Non-reactive & $44(29.13 \%)$ \\
\hline Not applicable & $17(11.25 \%)$ \\
\hline Unknown & $19(12.58 \%)$ \\
\hline Children Status (N=197) & $71(47.01 \%)$ \\
\hline Any child reactive & \\
\hline Any child non-reactive & $7(3.55 \%)$ \\
\hline All children reactive & $3(1.52 \%)$ \\
\hline All non-reactive & $2(1.01 \%)$ \\
\hline Status unknown & $30(15.22 \%)$ \\
\hline Not applicable & $131(66.49 \%)$ \\
\hline Pattern of risk behavior (N=164) & $24(12.18 \%)$ \\
\hline Regular partner/spouse & \\
\hline Parent to child & $36(21.95 \%)$ \\
\hline
\end{tabular}




\section{Figures}

FIGURE 1 DISTRIBUTION OF ICTC CLIENTS AND REACTIVE CASES OVER A TIME PERIOD FROM JANUARYDECEMBER, 2019 ( $N=28876)$

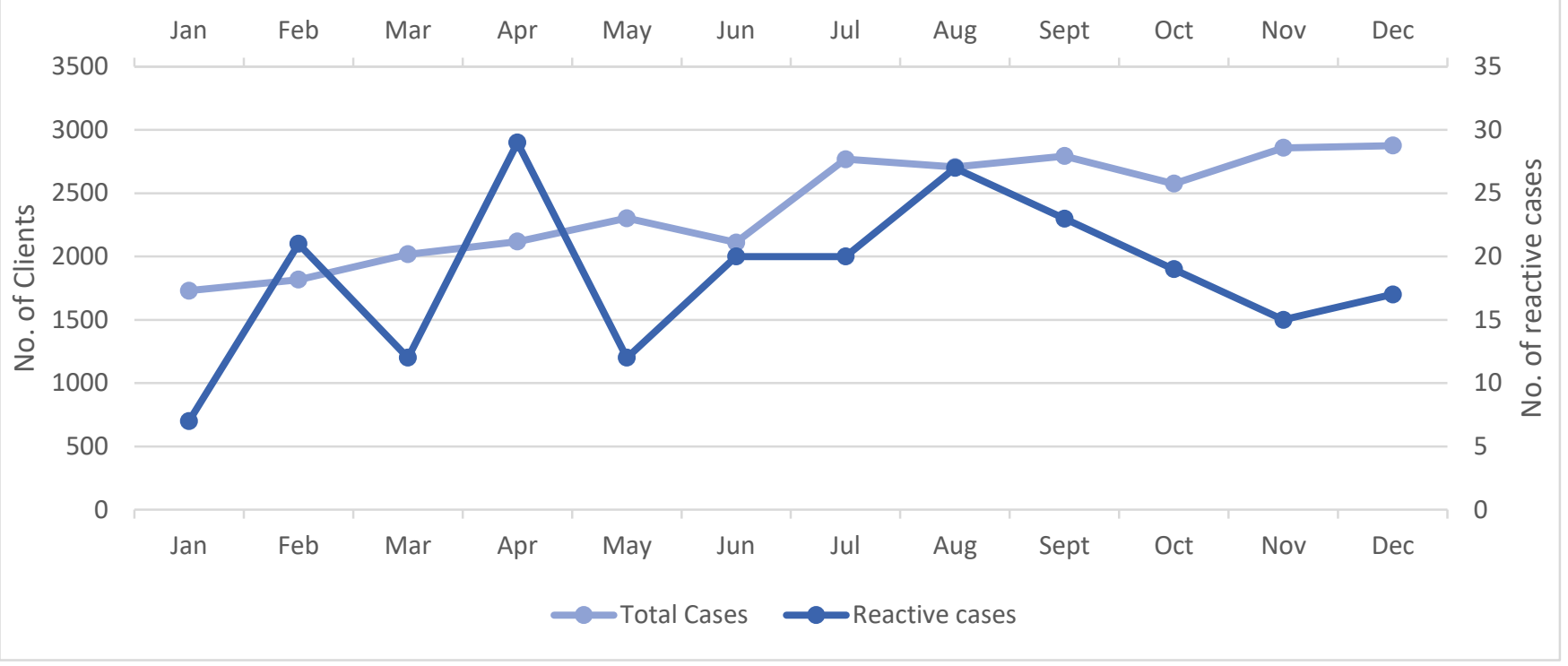

FIGURE 2 PROPORTION OF REACTIVE CASES (N=176) FROM DIFFERENT ADMINISTRATIVE DIVISIONS OF BIHAR

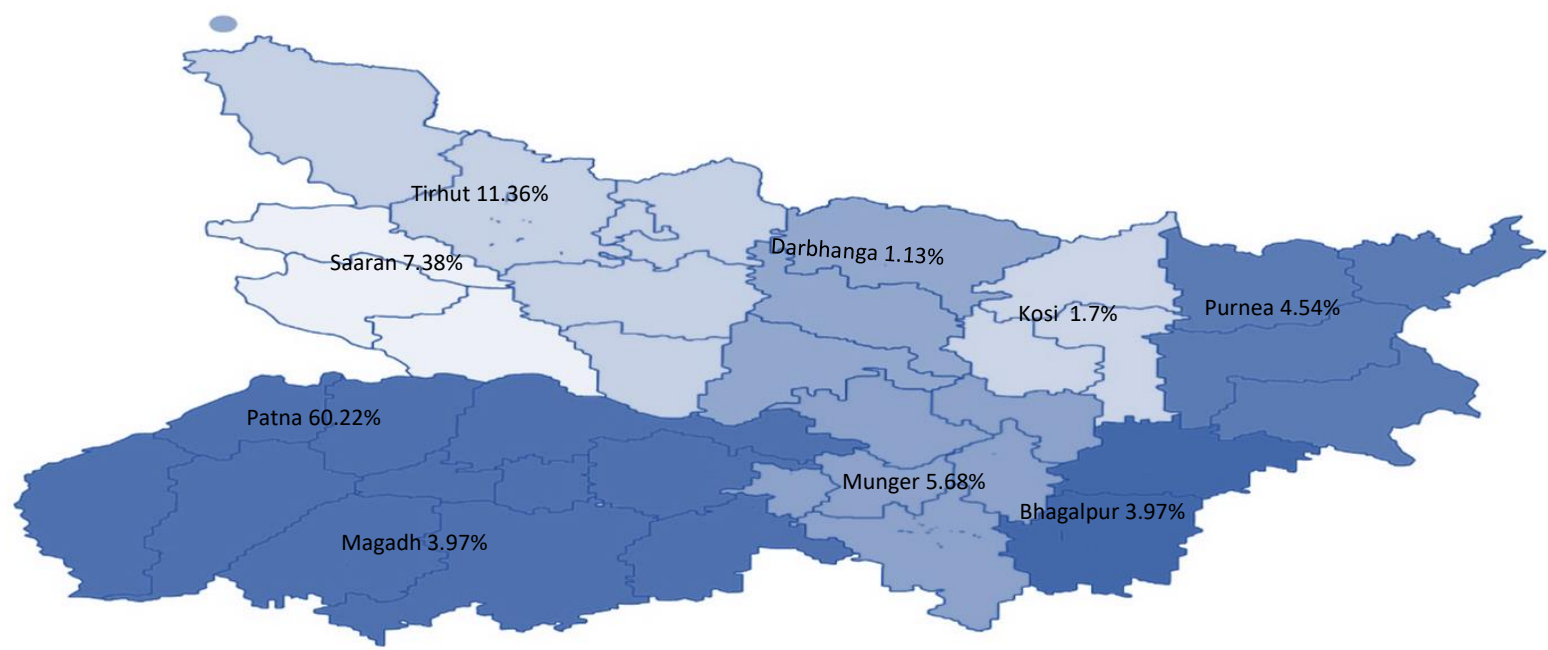

